\title{
ESPIRITUALIDAD JUVENIL EN CHILE HOY: CARACTERÍSTICAS Y ÁMBITOS
}

\author{
CARMEN SILVA DREYER* \\ JAVIER ROMERO OCAMPO ${ }^{* *}$ \\ TOMÁs PETERS NÚÑEZ ${ }^{* * *}$
}

\begin{abstract}
RESUMEN
El presente artículo muestra los resultados de un estudio de carácter exploratorio que analiza algunas características generales que definen la espiritualidad de jóvenes chilenos en el contexto actual. En las últimas décadas la sociedad chilena ha experimentado fuertes tensiones entre los procesos de autonomía de los individuos (individuación) y el de las instituciones sociales (individualización), lo que también es evidente en relación a los jóvenes y las instituciones eclesiales (especialmente la católica). A partir de un estudio cualitativo - basado en cuatro grupos focales, conformado por jóvenes de ambos sexos, de 17 a 20 años y de niveles socioeconómicos medio bajo y medio alto- los resultados revelan que en la espiritualidad de estos jóvenes, asume mayor importancia la experiencia individual y se prescinde, en parte, de los caminos prescriptivos ofrecidos por las instituciones eclesiales, enfatizándose la apertura hacia las experiencias ancladas en nuevos espacios de sentido.
\end{abstract}

PALABRAS CLAVE: JUVENTUD, ESPIRITUALIDAD, RELIGIOSIDAD, INDIVIDUACIÓN, INDIVIDUALIZACIÓN

* Psicóloga, Magíster en Psicología Social-Comunitaria, Investigadora Centro de Investigaciones Socioculturales de la Universidad Alberto Hurtado, Chile. Correo electrónico: casilvdr@uahurtado.cl.

** Profesor de Historia y Geografía, Sociólogo y Psicólogo, Doctor (c) en Estudios Americanos. Investigador Centro de Investigaciones Socioculturales de la Universidad Alberto Hurtado, Chile.

Correo electrónico: jaromero@uahurtado.cl.

*** Sociólogo, Magíster (C) en Teoría e Historia del Arte. Investigador Centro de Investigaciones Socioculturales de la Universidad Alberto Hurtado, Chile. Correo electrónico: tpeters@uahurtado.cl.

Nuestros agradecimientos y especial reconocimiento a Katherine Gilfeather, M. M., por su valiosa inspiración y aportes. 


\title{
ESPIRITUALIDADE JUVENIL NO CHILE DE HOJE: CARACTERÍSTICAS E ÂMBITOS
}

\begin{abstract}
RESUMO
Este artigo mostra os resultados de um estudo exploratório que analisa algumas características gerais que definem a espiritualidade de jovens chilenos no contexto atual. Nas últimas décadas, a sociedade chilena tem vivido fortes tensões entre os processos de autonomia dos indivíduos (individuação) e das instituições sociais (individualização), o que também é evidente em relação aos e às jovens e as instituições eclesiásticas (especialmente a católica). A pesquisa parte de um estudo qualitativo feito com quatro grupos focais constituídos por jovens de ambos os sexos, de 17 a 20 anos, de níveis socioeconômicos médiobaixo e médio-alto. Os resultados revelam que, na espiritualidade dos jovens, o mais importante é a experiência individual, prescindindo, em parte, os caminhos prescritivos oferecidos pelas instituições eclesiásticas, enfatizando-se a abertura às experiências ancoradas em novos espaços de sentido.
\end{abstract}

PALAVRAS CHAVE: JUVENTUDE, ESPIRITUALIDADE, RELIGIOSIDADE, INDIVIDUAÇÃO, INDIVIDUALIZAÇÃO

\section{YOUTH SPIRITUALITY TODAY IN CHILE: CHARACTERISTICS AND FIELDS}

\begin{abstract}
This paper presents the results of an exploratory research which analyzes a few general characteristics of Chilean youth spirituality in the current context. In the last decades, the Chilean society has experienced strong tensions between the individual autonomy processes (individuation) and those from the social institutions (individualization), which is also obvious in the case of youth and the ecclesiastical institutions (specially the catholic ones). Using a qualitative method, based on four focus groups composed by female and male youth, aged 17 to 20, from middle low to middle high socioeconomic level, the results show that the individual experience is salient in their spirituality, and that they partially disregard the ecclesiastical prescriptions and highlight the openness to experiences anchored in new fields that make sense to them.
\end{abstract}

\author{
KEY WORDS: YOUTH, SPIRITUALITY, RELIGIOSITY, \\ INDIVIDUATION, INDIVIDUALIZATION
}




\section{INTRODUCCIÓN}

DESDE MEDIADOS DEL SIGLO XX las ciencias sociales han discutido profusamente la denominación conceptual de nuestro período histórico. Para algunos, estaríamos en presencia de una modernidad tardía (Giddens, 1997) y, para otros, en una modernidad líquida (Bauman, 2003). Es más, algunos proponen que la modernidad sería aún un proyecto inconcluso (Habermas, 1998). Lo cierto es que, a nivel general, los autores reconocen la complejización de la tensión entre la experiencia individual y los nuevos fenómenos de la globalización (Giddens y Beriain, 1996). Esta trayectoria, caracterizada por la complejización y flexibilización de los órdenes sociales tradicionales (Wagner, 1997), ha generado demandas concretas tanto en las instituciones sociales como en los individuos. Ya no basta, para estos últimos, definir su vida por las condicionantes estructurales (género, educación, ingreso, religión, etc.), sino que se ven empujados a definir sus propios proyectos biográficos y a sostener sus propias decisiones vitales (PNUD, 2002). Con las instituciones sociales ocurre algo similar: se ven compelidas a diferenciarse, especializarse y a guiarse por los propios fines (Bilbao, 2007). Esta doble tendencia genera desafíos múltiples a la organización de la vida social (Giddens, 1984; Archer, 1997). La necesaria dependencia mutua entre la subjetividad de las personas y la organización institucional de la sociedad se ve tensionada por aquella doble llamada a la autonomía (Beck y Beck-Gernsheim, 2003). Producir y asegurar esa dependencia mutua es la tarea propia de la cultura (Güell, 2008). De ahí que estos cambios impliquen un gran desafío social y cultural para las sociedades actuales.

Desde la década de los noventa hasta la actualidad, en Chile se ha producido un importante y acelerado cambio social y cultural (PNUD, 2002 y 2010). Los jóvenes chilenos de ambos sexos, específicamente han vivido con mayor cercanía estos nuevos y contingentes cambios. Ellos se ven enfrentados permanentemente a las tensiones surgidas entre los ordenamientos institucionales y sus propias decisiones de vida (PNUD e INJUV, 2004). En este marco, las motivaciones y horizontes de expectativas de los jóvenes se van construyendo en torno a su adscripción u oposición a las instituciones. Los jóvenes disponen de amplios márgenes de decisión y, por cierto, de experimentación, lo que les permite radicalizar sus modos y conductas de vida y definir, con el tiempo, nuevos y alternativos proyectos vitales. Este proceso, teorizado como individuación (Martuccelli y Araujo, 2010), nos permite ampliar nues- 
tras maneras de observar el mundo juvenil y, a la vez, comprender las nuevas formas de apropiación de los modos de vida que los hombres y mujeres jóvenes chilenos desean diagramar en su presente y futuro.

Por otra parte, la institución religiosa tampoco está ajena a este escenario histórico. Bajo la condición actual de la sociedad moderna, las instituciones eclesiales — especialmente la Iglesia católica — han debido enfrentar los desafíos que les plantean estos nuevos procesos de individuación. Específicamente en el ámbito religioso, dichos procesos están asociados a un cuestionamiento de verdades heredadas y del teísmo clásico caracterizado por sus modos monárquicos de gobierno. Este teísmo parece, por tanto, no satisfacer la búsqueda actual de Dios en un contexto sociocultural donde los valores de la modernidad tardía se radicalizan. Bajo esta condición histórica, surge un desencanto con la racionalidad moderna y un aprecio por la pluralidad, emocionalidad, corporalidad, solidaridad, y conexión del ser humano con la naturaleza (Beck y Beck-Gernsheim, 2003; Bauman, 2001; Giddens, 1992).

Lo anterior genera la emergencia de nuevas ofertas religiosas coherentes con el complejo proceso en ciernes. Ya no basta ceñirse a los ritos y modelos estandarizados de antaño o a las lógicas tradicionales que, para otras generaciones, aseguraban estabilidad institucional e individual. Las instituciones, en general, deben especializarse y flexibilizarse en sus propias operaciones, para, con ello, ofrecerles a los individuos opciones de entrada y salida más adecuadas a sus nuevas demandas y necesidades. Este proceso, conceptualizado como individualización, permite comprender cómo el aumento de la diferenciación, autonomía y flexibilidad de las instituciones sociales modernas — como la religiosa - conforman lógicas de acción inéditas radicalizando la capacidad de los sujetos en la configuración de sus proyectos vitales a partir de su relación con las instituciones y, a la vez, tomar una distancia pragmática suficiente (Beck y Beck-Gernsheim, 2003).

Por lo tanto, entre la individuación de los hombres y mujeres jóvenes y la individualización de las instituciones hay una serie de hechos concatenados. Los hombres y mujeres jóvenes deben configurar su proyecto de vida en base a las instituciones sociales y estas últimas deben reformular y/o adecuarse a las exigencias de los sujetos. Sin embargo, este juego de relaciones es permanente fuente de tensiones, desafíos y búsquedas, muchas veces no exenta de dificultades. Esto genera conflictos culturales en la sociedad, ya que los individuos necesitan, para cumplir con sus proyectos vitales, de referentes institucionales que permitan ofrecer lógicas de integración y de sentido. Si aquello no ocurre, surgen 
permanentemente cuestionamientos de los jóvenes, e.g., hacia las instituciones y autoridades religiosas, ya que ellas, muchas veces, cuestionan las ganancias de autonomía que los jóvenes han logrado en estos últimos años. La Iglesia católica, en respuesta de este proceso, ha desplegado una serie de estrategias concretas para hacer frente a este proceso. En el caso chileno, el surgimiento de la Vicaría de la Esperanza Joven en los años noventa es un claro ejemplo del esfuerzo por resolver adecuadamente la tensión descrita. Esto en medio de paradojas tales como el mantenimiento, de parte de los jóvenes, de referencias positivas hacia lo religioso, en conjunto con un progresivo abandono de las prácticas religiosas, problematizando con ello la relación.

Dentro de las referencias positivas que muestran los jóvenes respecto de la religión podemos decir que, si tomamos como referencia las Encuestas Nacionales de Juventud, realizadas por el Instituto Nacional de la Juventud (INJUV), observamos desde el año 1997 a la fecha, que el porcentaje de quienes se declaran católicos y evangélicos no baja del $65 \%$, por ello se puede afirmar que la identificación religiosa de los jóvenes aún sigue siendo mayoritaria. La V Encuesta Nacional de Juventud señala, concretamente, que un 56,2\% se declara católico y un 13,8\% se declara evangélico (INJUV, 2007:143). Esto lo corrobora un estudio realizado por CISOC (2005) que encuestó a alumnos de cuarto medio de colegios católicos y laicos. El porcentaje de alumnos de colegios laicos que declaran pertenecer a la religión católica fue de 46,6\%. En el caso de los colegios católicos, la proporción de alumnos de esa religión ascendía al 70,6\%. Esta última cifra marca un descenso de 11,6 puntos porcentuales si se la compara con la que se obtuvo en un estudio realizado hace quince años con una muestra de alumnos de cuarto medio de colegios católicos de Santiago. ${ }^{1}$

En cuanto a las creencias, se observa que, según la V Encuesta Nacional de Juventud, los porcentajes referidos a la alta creencia en Dios, Jesucristo, los Ángeles y los Santos, se encuentran todos por sobre el $50 \%$. Estos datos son coincidentes con la citada encuesta de CISOC que

1 En esta investigación realizada en 1989 el porcentaje de alumnos que declararon ser católicos llegó al 82,2\%, sobre la base de una muestra de 499 alumnos de cuarto medio de colegios católicos de diversos niveles socioeconómicos de Santiago (Harriet y Valdivieso, 1990:67). Un estudio realizado hace más de diez años y sobre la base de encuestas a 643 alumnos de cuarto medio de Santiago y Concepción dio como resultado un 59,1\% de católicos (Mideplan, 2000:101). 
señala que la creencia en Dios, tanto en jóvenes de colegios católicos como no católicos, sobrepasa el 70\%, y específicamente las imágenes de Dios que más se valoran son la de un Dios como padre bondadoso, omnipresente y creador. En cambio, las menos valoradas son las imágenes de Dios como juez supremo, indiferente y castigador.

Dentro de las tendencias que señalan cambios en la relación de los jóvenes con la religión destaca, en primer lugar, la escasa práctica religiosa de los hombres y mujeres jóvenes, rasgo muy característico de nuestro tiempo. La V Encuesta Nacional de Juventud muestra que quienes asisten semanalmente a ceremonias y templos, exceptuando ceremonias de matrimonio, bautizo o funeral, son un $13,4 \%$. Por su parte, los que asisten una vez al mes corresponden a sólo un 6,7\%, y los que asisten sólo ocasionalmente un $33,7 \%$. Quienes «nunca» asisten llegan a un 44,1\%. Un 12,2\% de los jóvenes católicos de ambos sexos acuden semanalmente, una vez al mes un 9,4\%, sólo ocasionalmente un 46,4\%, y nunca un 31,9\%. El estudio de CISOC (2005) señala que el 8,6\% de los jóvenes católicos de ambos sexos asiste a misa todos los domingos o más, el 17,5\% lo hace algunos domingos al mes, un 53,9\% participa sólo ocasionalmente de esta celebración, y el $19,5 \%$ no lo hace nunca. Considerando a los alumnos católicos que estudian en colegios de iglesia, la cifra de asistencia a misa semanal o más, es también de 8,6\%; mientras que hace quince años asistían una vez a la semana o más, el 27,6\% (Harriet y Valdivieso, 1990:70). En cuanto a la práctica de comulgar, los jóvenes católicos que lo hacen todos los domingos al mes o más llegan al 4,8\%; algunos domingos al mes el 13,5\%, ocasionalmente el 44,6\%; y quienes no lo han hecho en el último año ascienden al 36,3\%. El sacramento de la reconciliación no ha sido celebrado ninguna vez en los últimos doce meses por el $58,4 \%$ de los jóvenes católicos de ambos sexos, mientras que alrededor de un tercio $(31,3 \%)$ lo ha celebrado una o dos veces en ese período de tiempo, y un 9,5\% se ha confesado tres veces o más en el año. ${ }^{2}$ Considerando las tres prácticas que corresponden a «mandamientos de la iglesia», hay sólo un 6,3\% de los católicos que las cumplen.

2 Estadísticas de diversos países confirman que ha habido una disminución bastante generalizada de la frecuencia de confesiones en años recientes, y que algunos católicos recurren a alternativas terapéuticas, más que al confesionario. Por otra parte, existe también la creencia, entre católicos, de que el perdón de Dios puede lograrse sin tener que recurrir al sacramento (CISOC, 2003). 
Un aspecto relacionado con lo anterior es el creciente menor grado de confianza en la institución eclesial, particularmente la Iglesia católica, por parte de los y las jóvenes. La V Encuesta Nacional de Juventud, señala que la Iglesia católica se ubica en quinto lugar de confianza entre diversas instituciones, y los sacerdotes, pastores o monjas obtienen un quinto lugar en cuanto a la confianza en personas. Las críticas, según el citado estudio de CISOC (2005), se focalizan en la inconsistencia entre discurso y práctica, intromisión en temas políticos y promoción de una moral sexual extemporánea. En el mismo estudio, el aspecto mejor evaluado es la cercanía y acción hacía excluidos y pobres. Al preguntarles por las características que definirían a un buen católico, los hombres y mujeres jóvenes destacan la honradez, la ayuda a los pobres y la confianza en Dios, dejando en los últimos la práctica cultual, la obediencia a las autoridades eclesiásticas y las orientaciones en materias de sexualidad y moral familiar.

Además de estas afirmaciones, hay algunas tendencias que están en proceso de desarrollo, la primera de ellas a destacar es la importancia creciente de quienes en las diversas encuestas se autodefinen como no pertenecientes a ninguna religión. La V Encuesta Nacional de Juventud nos muestra que este grupo representa un $24,5 \%$, y en el estudio de CISOC llegan a un 19,5\% en los colegios católicos y a un $30,1 \%$ en los colegios no católicos. Asimismo, a nivel de creencias no cristianas hay un avance creciente. La V Encuesta Nacional de Juventud muestra que la creencia en la astrología llega a un 30,6\%, la creencia en la reencarnación a un $35,6 \%$, en la magia a un $25,7 \%$ y en el tarot e I ching a un 23,0\%. En el estudio de CISOC, el 29,8\% de los alumnos católicos consulta tarot e I ching y una minoría de $9,5 \%$ ha asistido a celebraciones no católicas. ${ }^{3}$

Sin embargo, al analizar la tensión entre religiosidad y espiritualidad, entendida la primera como un sistema organizado de creencias y cultos de la religión, lo que involucra conocimientos, comportamientos, normas, ritos y valores conectados con creencias y ritos de una religión en particular, eminentemente social (Peteet, 1994); y la espiritualidad, a su vez entendida como la experiencia de lo divino, siendo su naturaleza, individual, singular, específica y personal (Emblen, 1992). Según la evidencia detectada en países latinoamericanos (Tinoco-Amador, 2009), la espiritualidad y religiosidad juvenil ha experimentado nuevas y dife-

3 Según el estudio de Mideplan, un 25,9\% de los estudiantes de cuarto medio había consultado el tarot, I ching, horóscopo (Mideplan, 2000:103). 
rentes lógicas de experimentación. Los libros de autoayuda, el seguimiento de nuevos credos, las prácticas deportivas basadas en lógicas de oración oriental, etc., nos entregan antecedentes concretos de que la espiritualidad y religiosidad no se vacían tan fácilmente. Ahora bien, Mardones señala que esta nueva espiritualidad se daría de una forma tal que en términos descriptivos sería «...un clima o sensibilidad espiritual más que un movimiento espiritual estructurado. Expresa una actitud o un ansia unitaria armónica, por conjugar lo personal y privado con lo ecológico y lo cósmico, lo libre y sin trabas con la experiencia profunda y natural con lo divino en el fondo de todo» (Mardones, 1980: 123).

La menor participación en rituales religiosos, pero la mayor valoración de la experiencia interior y la búsqueda de sentido por medio de nuevos y diversos referentes espirituales exigen desarrollar reflexiones y estudios que ofrezcan evidencia sobre cómo se están zanjando las búsquedas espirituales y/o religiosas de los jóvenes en un contexto donde la ampliación de opciones de proyectos vitales cada vez más se radicalizan. Esta necesidad de estudios se justifica aún más en virtud de que los trabajos existentes sobre religiosidad juvenil se basan en indicadores de religiosidad tradicionales, no logrando así pesquisarse las nuevas formas de espiritualidad que puedan estar surgiendo.

En base a este contexto, es pertinente preguntarse ¿cómo es la espiritualidad de los hombres y mujeres jóvenes que participan y no participan en la Iglesia católica? Específicamente, ¿cómo es su relación con Dios y qué imagen tienen de Él? ¿Qué significa Él en sus vidas? ¿Cuáles son sus expresiones espirituales y símbolos? ¿Cuáles son las consecuencias de esta espiritualidad en cuanto al comportamiento prosocial? ¿Cómo perciben a la Iglesia católica y qué significado tiene para ellos? ¿Cuáles son los ámbitos en los que buscan la trascendencia, se expresa su espiritualidad en sus actividades preferentes, su sentido de vida, sus valores?

Responder estas preguntas nos permite ofrecer antecedentes críticos para reflexionar y cuestionar las nuevas lógicas de integración social. Específicamente, nos permite comprender los desafíos tanto institucionales — de la Iglesia católica — como individuales — jóvenes - que se requieren para establecer una sociedad más reflexiva y tolerante con la diferencia. De la misma forma, permite conocer qué estrategias realizan los jóvenes chilenos para suplir las carencias de sentido que la institución religiosa, eventualmente, puede estar dejando de ofrecer, y posibilita, además, conocer los nuevos significados que le otorgan los jóvenes a la experiencia religiosa. 
Los datos aquí presentados permitirán suplir, en parte, el vacío analítico y empírico que ha existido en Chile en los últimos años sobre las nuevas formas de experimentar lo religioso por parte de un individuo cada vez más autodeterminado y conectado con el mundo: los hombres y mujeres jóvenes.

Este artículo corresponde a la fase cualitativa y final del estudio «Jóvenes: orientaciones valóricas, religión e iglesia católica» desarrollado por el equipo de investigación del Centro de Investigaciones Socioculturales de la Universidad Alberto Hurtado (CISOC, 2005) y cuyo objetivo fue profundizar, desde una perspectiva subjetiva de los participantes, su espiritualidad.

\section{EXPLICACIONES METODOLÓGICAS}

Para el presente estudio se utilizó un diseño metodológico cualitativo, debido al carácter eminentemente exploratorio del problema de investigación. Su uso radica, principalmente, porque es un fenómeno que no cuenta con un cuerpo teórico suficiente que permita la formulación de hipótesis a verificar. De la misma forma, y al no contar con indicadores tradicionales provenientes de conocimientos preexistentes, la metodología cualitativa permite comprender las nuevas expresiones del fenómeno religioso por la amplitud para crear categorías conceptuales nuevas que emerjan directamente de los contenidos verbales de los participantes. Para ello se ha utilizado la teoría fundamentada (Strauss y Corbin, 1990), que permite explorar las percepciones subjetivas de los participantes.

Participantes. La muestra estuvo conformada por 26 jóvenes, de ambos sexos, que cursaban su cuarto año de enseñanza media en cuatro establecimientos educacionales católicos y no católicos de la Región Metropolitana de Santiago. Sus edades fluctuaron entre los 17 y 20 años y su nivel socioeconómico correspondía a medio bajo y medio alto.

El número de participantes se vinculó al criterio de saturación de la información de las categorías emergentes. La edad fue determinada en base a la etapa de la adolescencia tardía, de preocupación por su futuro y su postura valórico-ideológica en la conformación de su identidad. El nivel socioeconómico fue determinado por el criterio de financiamiento del colegio (de tipo particular o subvencionado por el Estado), y por su naturaleza científico-humanista o técnico. El estudio se efectuó en aquellos establecimientos que accedieron a participar, de entre una lista de éstos. 
Instrumentos. Se organizaron cuatro grupos focales - uno por colegio - y cada uno estuvo conformado por entre seis a ocho jóvenes, a quienes se les aplicó una pauta de entrevista semiestructurada, confeccionada a partir de un guión temático basado en las preguntas directrices del estudio. Las dimensiones a indagar fueron: i) la representación y relación con Dios; ii) significado e importancia de Dios; iii) consecuencias de su espiritualidad; iv) visión de la Iglesia católica; y v) espacios, ámbitos y expresiones de sentido de vida y espiritualidad.

Procedimiento. Los jóvenes de ambos sexos fueron contactados en el colegio, conformándose los grupos focales en el lugar. Los investigadores a cargo del proyecto condujeron las entrevistas, previo consentimiento de los participantes. Se les explicó el motivo de esta actividad, su confidencialidad y se les entregó una pequeña compensación al finalizar la entrevista. Las sesiones fueron audiograbadas y tuvieron una duración de una hora y media a dos horas aproximadamente cada una.

Análisis. La información obtenida a través de los grupos focales fue sometida a análisis de contenido a nivel descriptivo y relacional, según la teoría fundamentada (Strauss y Corbin, 1990). Se realizó una codificación abierta de las respuestas de cada entrevista, identificando y clasificando categorías conceptuales (nodos) que dieran cuenta de los contenidos. Ellas se articularon luego en árboles de categorías. Posteriormente, se efectuó la codificación axial, estableciendo relaciones entre categorías. Todas ellas fueron organizadas —asignándoseles un nombre o concepto abstracto- en torno a fenómenos emergentes, los que constituían núcleos articuladores del significado. Estos hallazgos esenciales eran transversales a los datos. A partir de ellos, se construyó un modelo comprensivo de la espiritualidad de estos jóvenes, cuyos resultados se describirán a continuación. Con el fin de facilitar la lectura y no interrumpir el hilo argumentativo, se omitió el nombramiento de los componentes de cada fenómeno axial, conocidos como «propiedades», «antecedentes», «estrategias de acción», «consecuencias» y «condiciones intervinientes», quedando implícito en el texto.

\section{EXPOSICIÓN DE RESULTADOS}

La pregunta sobre cómo es la espiritualidad de los hombres y mujeres jóvenes se responde a partir de varios fenómenos emergentes de los datos. Éstos apuntan a la relación con Dios, por una parte, y a motivaciones que dan sentido a sus vidas o por las que reportan que vale la pena existir, por otra. 
Algunos de los fenómenos abarcan específicamente las preguntas sobre la relación con Dios, la imagen y significado de Él, expresiones espirituales, consecuencias de espiritualidad y percepción de la Iglesia católica. Otros, en cambio, manifiestan los ámbitos en que se expresa su espiritualidad implícita o explícitamente en aquello que da sentido a sus vidas.

a) Relación con Dios, imagen y significado de Él, expresiones y consecuencias de la creencia, y visión de la Iglesia católica

Los jóvenes creen en Dios y se relacionan con Él, señalando necesitarlo. Su imagen de Dios es positiva, atribuyéndole características tales como el no tener una forma material, ser el Todo y estar en Todo. Vale decir, estar dentro de la Creación y más allá de ésta (en las personas, en el amor, en la otra vida después de la muerte, somos parte de Él). De la misma forma, ser una fuerza, ser perfecto en ser y hacer, ser grande, ser el amor con todas sus cualidades (comprensión, compañía, ayuda, etc.), y ser maestro. La relación de los jóvenes de ambos sexos con Dios es experimentada en forma individual por algunos, $\mathrm{y}$ asistiendo a la iglesia por otros, formas que se describirán a continuación.

\section{i) Relación individual con Dios}

Las respuestas apuntaron reiteradas veces a una fuerte posición crítica ante la Iglesia católica y a la opinión de que la iglesia es prescindible en la relación con Dios. Se cree que Dios, como ser omnipresente, no requiere de un lugar de adoración especial o de la pertenencia a un grupo particular, ya que está presente en todo lugar. «Igual, no es necesario ir a rezar también a la iglesia, sino que también uno puede ir a rezar a cualquier lado» (EI, 311).

No hay por qué estar ahí, alabando al Señor, como algunos lo hacen en las calles, otros lo hacen en una iglesia; si uno está sentado en una plaza, y está tranquilo con uno y conmigo, está tranquilo con todo el mundo [...] Estar en donde sea. (EIV, 331).

Pero en ninguna de las dos [iglesias] yo creo que está Dios. Porque igual de repente antes leía la Biblia y nunca hemos estado en una iglesia. Que decía que cuando levantara una piedra iba a encontrar a Dios, 
cortando un madero y va a estar Dios. Entonces por qué hicieron iglesias, poh? Es como para estar, como para meter gente (EIV, 337).

Se cuestiona la actitud inconsecuente de los fieles. Ésta se expresa en comportamientos desenfrenados en fiestas, prácticas automatizadas vacías de sentido, soledad en celebraciones religiosas numerosas y asistencia a misa sin el correspondiente comportamiento solidario.

Porque yo he visto personas no sé poh, porque se supone que Dios le ayuda al prójimo y hay personas que van a la iglesia y yo he visto personas que no ayudan (EI, 286).

Otras críticas apuntan a la exclusión de los separados, a normas consideradas ridículas y anticuadas sobre todo en el plano de la moral sexual, a una iglesia contraria a sus opiniones, a manipulación e imposición de visiones, tomar una posición que sólo corresponde a Dios y hablar por Él. La iglesia tiene poca credibilidad a sus ojos, la ven rutinaria, sin cambios. La misa les parece aburrida.

Como que empieza así a hablar, repite, repite, al final uno está, la oratoria del cura, del padre, de monseñor o lo que sea que se volvió una cosa tradicional y hay gente que por ejemplo, yo tengo tías que van y pa' ella es ir como una cosa sagrada y van a rezar, pueden ir con los ojos cerrados y se saben agachar en los momentos que tienen que agacharse, entonces se vuelve como una cosa así como muy metódica, una cosa automática o sea que eso llega se pone a rezar un padrenuestro, uno cree que está contento, pero si no lo hace de corazón o conscientemente no le veo la gracia (EII, 388).

La relación individual se caracteriza por un vínculo de conciencia y de corazón — como se lee arriba—, no ajustándose a prácticas normadas.

Sí, yo creo que se va a sanar la relación [...] con Dios, no como en la estructura de la misa, no, yo creo que la cosa profunda está en cada uno, en cada uno y en lo que siente y las cosas que crea (EIII, 137).

La relación con Dios se experimenta en determinados espacios y momentos de la vida. En cuanto a los espacios, sienten la presencia de Dios en una diversidad de lugares, no circunscritos al espacio eclesial. Estos remiten a la naturaleza y a espacios abiertos, a la propia pieza (oración nocturna) y a personas que sufren, que son puras o queridas (papá, abuela, etc.). 
Cuando fui yo [...] al Hogar de Cristo, vi a unos abuelitos, abuelita que me decía que yo era buena, me decía, tenía como su, era como limpia, y no sé, yo la vi y sentí ganas de llorar, quería puras ganas de llorar porque era como, no sé, veía como a Dios en ella. Claro, poh, es como especial, porque a Dios lo veo en las personas (EIV, 172).

[Lugares donde comunicarse con Dios] Estando solo, en una plaza, algo así, no encerrado [...] libre, libre. [...] Yo de repente, yo cerca de mi casa tengo un parque y me voy a, hay un, como un cerro, y hay una punta así. Entonces ahí uno, me voy ahí y ahí me quedo, y como que el aire así, como que [inspira hondo], es rico porque el aire como que le, no sé, es bacán. Yo como que me rajo caleta de repente ando así, [...] y tiro todo, y me voy pa llá y ando así como que, relajo, así [...] Estar sola así, como que me limpio (EIV, 342,344).

Los momentos en los que se experimenta una relación con Dios refieren a situaciones en las que el joven se siente emocionalmente tocado por algo, ya sea en términos de malestar o de agradecimiento y alegría. Allí sienten a Dios principalmente como un apoyo, como una fuerza que ayuda a avanzar, y como una protección.

Las acciones que realizan en función de la relación con Dios son rezar y conversar con Dios en forma personal. Esto ocurre ya sea en la mañana, o en la noche antes de dormir, o bien en diferentes momentos de intimidad en soledad en cualquier lugar. No requiere de gestos tradicionales y refiere a diferentes motivos. A esta forma de oración, se suma algún rezo tradicional, como el Padrenuestro.

Yo de repente, cuando voy caminando voy, en la mente no más voy hablando con Él. Le pregunto cosas. De repente le digo: ¿por qué no me ayudas? Si de verdad eres grande [...] (EIV, 124).

Tienen objetos y gestos personales muy diversos que los conectan con Dios, con afectos personales positivos y relaciones humanas en que experimentan amor. Algunos de ellos son el despedirse de los seres queridos con un abrazo, beso y deseo de que estén protegidos, y atesorar un objeto significativo. Entre los objetos nombrados se cuentan un cuadro del ángel de la guarda, unas cadenitas, una cinta recuerdo de bautizo, santitos de la Virgen, cartas de confirmación, una cruz, un rosario, pequeños objetos de recuerdo guardados en la Biblia, vestimenta con valor simbólico usada en algún servicio social, entre otras. Significan sobre todo seguridad, apoyo, protección, afectos positivos que surgen de relaciones de cariño, un sentirse capaz, digno y acom- 
pañado por Dios y empatía con quien está sufriendo. Están muy relacionados con personas que se quieren, con amar y ser amado.

Yo tengo un rosario [...] me lo obsequiaron a mí [...] la tía Mimi. [Entrevistador: ¿y qué te pasó con eso cuando te lo regaló?] No, si igual, como más afecto (EI, 363, 368, 370, 371).

Yo tengo en mí, yo tengo un ángel de la guarda en mi pieza [...]. No, es que mi mamá tiene una pieza, o sea, tienen una foto en mi pieza, po, se la pone arriba de mi hermano chico, porque tiene tres [años], y es un ángel de la guarda. Para mí igual así, creo que me va a pasar algo y me asusto que haya, que no esté más con mi hermano, y como que llega el ángel de la guarda y me ayuda. Y a mi hermano chico igual (EIV, 198).

No, yo, lo que tengo en mi pieza es una Biblia que me regalaron una vez. Una amiga me regaló una Biblia [...] Esa Biblia la tengo guardadita, todo lo que, como que o que es importante también lo guardo allí [...] cosas que me regalan a mí, fotos [...] (EIV, 210, 215, 219).

La forma individual de relación con Dios se asocia a la valoración de la libertad personal frente a las opciones posibles: «Entonces, o sea claro, debemos apegarnos a algo, pero creo que somos libres, tenemos libre albedrío para hacer lo que queramos, esté bien o mal» (EII, 279). Asimismo, la relación individual con Dios se ajusta más a la preferencia juvenil en general de las acciones espontáneas, no planificadas y poco estructuradas. «A mí me gusta jugar básquetbol en las tardes, y en las noches salgo a carretear, me voy para donde me lleven los pies» (EIV, 13).

Algunas consecuencias de la relación con Dios son la tranquilidad, relajación de las tensiones y bienestar emocional en general. Otro efecto apunta a un cambio de comportamiento en la línea de la prosocialidad y solidaridad para con los demás. «No sé po, es como a ver, como digamos como que me mantiene más relajao [...] mmm, como que me siento que Él me apoya, así como, más por eso» (EI, 177, 178).

Porque uno cuando no está con Dios anda haciendo maldades. Uno hace cualquier maldad, pero después cuando uno ya anda con Dios, anda preocupado de estar, ser bueno. Con un niñito así, de repente le puede pasar algo así, si uno anda como con Dios así, uno le ayuda. Pero si uno no está ni ahí, ahh, se cayó el cabro chico, ja, ja, ja. Después como que uno anda bueno así, uno le ayuda, cualquier cosa. Como que anda más preocupado de la gente (EIV, 164). 
ii) Relación con Dios mediada por la iglesia

Hay jóvenes que, a la par de mantener una relación personal con Dios y prácticas compartidas con los jóvenes que tienen una relación individual con Dios, se diferencian de éstos por tener algún grado de participación en la iglesia y una postura más positiva frente a ella. Para ellos, la iglesia es concebida como un vínculo con Dios, la aprecian y se sienten a gusto en ella, aunque compartan algunas críticas.

Estos jóvenes han participado en diferentes instancias eclesiales, como el movimiento Encuentros de Jóvenes en el Espíritu (EJE), la parroquia, misiones y retiros de colegio, y en actividades organizadas por la Vicaría de la Esperanza Joven.

A estas acciones se suman las mismas prácticas que efectúan los jóvenes que sólo tienen una relación individual con Dios, en términos de gestos y objetos personales, formas de oración y momentos de comunicación con Dios. Igualmente, sienten a Dios principalmente como un apoyo, fuerza y protección.

Las consecuencias de su participación apuntan al bienestar emocional y las relaciones interpersonales positivas. Al respecto, hay una revalorización de los seres queridos y de la vida en general, un agradecimiento por las personas que los rodean y las cosas que se poseen.

Como que te acerca más, te das cuenta de cosas que no te habías dado cuenta. O sea, por ejemplo, veís todos los días a tu hermana y no te dai cuenta que $[\ldots]$ cosa rutinaria, pero tu querís a tu hermana, por decir tu hermana, puede ser una amiga, tus papás o de tu amigo, te dai cuenta de esas cosas, yo creo que eso te ayuda [...] (EII, 350).

En sus relaciones, los jóvenes también experimentan un cambio de comportamiento en la línea de la prosocialidad y la solidaridad. Los retiros, por ejemplo, estimulan la reflexión sobre la propia conducta negativa.

Pero ya en la noche como que todo lo que hiciste en la tarde se te olvidaba y hacías cosas contrarias y después ya como en el último día nos hicieron pensar ya, puta en la tarde hablaban de una cosa, en la noche hacían otra, nos hicieron pensar todo lo que hicimos y fue esa parte fue bonita (EI, 375.)

A su vez, los jóvenes experimentan entretención y amistad en el espacio eclesial: 
No, si nunca tanto como trasmitir, pero como, me gusta pasarla bien con los jóvenes, ah igual a lo mejor dicen ah este va a la parroquia va a pescar una piedra y se va a pegar en el pecho, no, yo voy más como pa’ divertirme (EI, 41).

En el plano de los afectos, manifiestan un sentimiento de paz, relajación de las tensiones, ánimo positivo, tranquilidad emocional, protección y seguridad, y acercamiento a Dios.

Igual como que me hicieron sentir más cerca de todo, cerca de Dios, cerca de, tenía más amigos, conocer personas que nunca las había visto, convivir con alguien, varias cosas (EI, 345) [alusión a retiros].

Me gusta ir a Lourdes porque soy muy despistada. A mí cualquier cosa me distrae fácilmente. O sea yo, como que igual no es cerrado, están las bancas no más, es como una carpita, y una piedra grande donde está la imagen de la Virgen y de Dios. Y está lleno de velas y se ve súper lindo y es como un patio grande. Entonces uno se relaja, es súper relajado. Como que nada te importa, como que estar solamente mirando la imagen ahí (EIV, 350).

Sus experiencias de iglesia son positivas y apuntan a iniciativas que han respondido a las inquietudes por medio de jornadas, retiros y misiones. No es rutinaria y se trabajan temas interesantes para los jóvenes de ambos sexos, entre los que se cuentan la familia, los amigos y el estudio. Además la perciben como espacio de apoyo y protección.

[¿ंTú sientes confianza en la iglesia?] Sí, porque en otras partes a uno le puede pasar cualquier cosa, uno nunca sabe, capaz que un día lo maten y nunca lo va a saber, pero adentro, si está ahí, se siente más seguro uno, como que es un lugar de todos los pobres (EI, 294 - 297).

Algunas críticas a la iglesia apuntan a su postura ante el tema del divorcio:

Claro, igual hay una contradicción que yo encuentro como que si la iglesia permite que uno se puede equivocar porque es humano, no todo nadie es perfecto [...] Porque si uno consideró que esta persona iba a ser su pareja de toda la vida, se equivocó, se dio cuenta que no, por qué la iglesia no permite el divorcio, por qué si yo me equivoque no (EIII, 150).

También critican a uno de los sacerdotes comentaristas de televisión, a la estructura jerárquica que excluye a los jóvenes de la toma de deci- 
siones, y a los laicos. También se critica el hecho que no esté ofreciendo una buena orientación, lo que induce a búsquedas de otras fuentes de sabiduría. Otro punto que se critica es la misa, que es percibida como aburrida, y la rutina en general en este ámbito.

Es que a mí me gusta como más eso. No me gusta la iglesia cristiana, como fome así, más rutinario, como que le dan tanto sentido a la cultura así [...] No sé, poh, lleva años siendo igual que no pueda cambiar (II, 327, 329) [opinión de joven que participa en Encuentros de Jóvenes en el Espíritu].

\section{b) Ámbitos de sentido de vida y espiritualidad}

La pregunta es sobre aquello a lo que otorgan sentido en sus vidas, por lo que reportan que vale la pena vivir, hecho que conecta con el sentido profundo de la espiritualidad. Al respecto, aparecen varias fuentes, que son la motivación de recogimiento e interioridad, la motivación de mantener vínculos de amor en el microsistema, la motivación de dinamismo, experimentación de sensaciones corporales y emocionales intensas, y la motivación de servir a otros a distintos niveles.

i) Motivación de recogimiento e interioridad

Los hombres y mujeres jóvenes experimentan una motivación por retirarse del mundo, desconectarse del acontecer con sus presiones, y volcarse hacia el interior de ellos mismos para reflexionar, meditar o recapitular:

Me gusta como salir sola a la playa y caminar y todo y ahí pienso mucho, me encanta porque siempre [...] las veces que voy, trato siempre como de salir sola y como caminar por la playa y todo, hago como un resumen de todo, como un repaso y me gusta mucho (EIII, 93).

Se acercan a la naturaleza, o crean una ambientación con un bajo nivel de estimulación y un efecto tranquilizador. Éstos constituyen espacios de silencio y belleza, entre los que figuran los parques, la pieza con luz tenue y otros. Asimismo, practican y asisten a otras expresiones culturales, tales como artes visuales, decoración, lectura, escritura, danza, yoga y, particularmente, música. Ésta los relaja, les trae recuerdos y un sentimiento de identificación con letras y melodías. 
Sí, a mí me pasa algo parecido, por ejemplo yo no sé igual no me siento muy bien, como llego, apago la luz, pongo música y como que me pongo a escribir o a dibujar, como que me relaja mucho, si es como que te centrai en ti te dai un tiempo (EIII, 87).

Las consecuencias observadas son la relajación, el olvido de tensiones y preocupaciones y en cambio, la generación de sentimientos de identificación, conexión con sus sentimientos y cambio a un estado emocional de bienestar.

Esta actitud de recogimiento se asocia a la definición de espiritualidad que plantean algunos jóvenes. Éstos describen la espiritualidad como el encuentro consigo mismo, la explicación del sentido y acontecimientos de la vida, la relación de armonía con el entorno y consigo mismo, una búsqueda única de cada persona, un sentimiento de estar bien, en paz y calma, un conocerse asociado a un momento de recogimiento personal, introspección y reflexión. La definen como la esencia única de cada persona en relación con Dios, consigo mismo y el universo. Dado que su relación personal con Dios se lleva a cabo en la intimidad y soledad, este factor de recogimiento facilita dicha relación.

ii) Motivación de vínculos de amor en el microsistema

Los hombres y mujeres jóvenes manifiestan que los vínculos de amor con la familia y los amigos constituyen un importante sentido de vida. Ellos valoran marcadamente estos vínculos, que consideran incondicionales, y aprecian la buena convivencia. Se refieren tanto a la familia de origen, como a la de procreación.

Para mí dar sentido a la vida es sacar a mi familia adelante, [...] a mi hermano (EI, 70).

Yo creo $[. .$.$] yo creo que ninguna persona es como tan [. .$.$] como en si$ misma que valga la pena vivir [...] poder existir y en cierta forma poder sobrevivir, yo creo que lo que nos hace estar en cierta forma todos acá el hecho claro de tener amigos, de tener a la familia, de querer al resto, uno por sí solo como que no es nada no tiene sentido, yo creo que obviamente la familia, los niños y todas esas cosas nos mueven y obviamente que las cosas buenas que podemos tener y obviamente la convivencia buena que podemos tener con ella (EIII, 65).

Argumentan que en momentos de dificultad, son ellos quienes se hacen presentes para brindar apoyo social. 
Pero al final, cuando a uno le pasa algo, cuando uno se cae, quien esta, o sea lo que uno tiene de ayuda no es la profesión sino son la, es la familia, son los lazos que tiene (EII, 122).

Esta valoración conlleva una inversión de tiempo en torno al hecho de compartir y crear lazos fuertes y permanentes. Las consecuencias de estas relaciones son percibidas como el crecimiento de la formación personal, el fortalecimiento del proceso de individuación, la adquisición de responsabilidad, la mitigación de dolor y sufrimiento, la donación y recepción de amor, y el apoyo en la debilidad. Los jóvenes perciben que su etapa es más propicia para cultivar estos lazos, proyectando una imagen de adultez con preocupaciones y limitaciones para dedicar tiempo a la amistad.

iii) Motivación de experimentar dinamismo, sensaciones corporales y emocionales intensas

Este fenómeno refiere a la motivación que los jóvenes manifiestan por sentir intensamente y gozar físicamente. Ellos califican estas experiencias como fundamentales en su vida. Arguyen que nada, ni la enfermedad, las puede detener. Se caracterizan por ser muy entretenidas y otorgar la posibilidad de disfrutar. Algunas de estas actividades se realizan en grupos, mientras que otras se llevan a cabo en soledad.

Yo hago ballet y es como pa’mí lo máximo, o sea si un día me siento mal tengo que ir a ballet no puedo quedarme en mi casa me sube demasiado el ánimo (EII 14).

Jugar skate me gusta, eeh, no sé, 5 años, 6 años tal vez [...] Una forma de llenar, como pasar el tiempo y descargar la energía, pero [...] sí, pero también es algo como que me llena, que no puedo decir algo que no me llena, porque es algo que me gusta demasiado, es cargar, es como dice la chica, es cargar energía (EII, 64, 67, 69).

Un antecedente que influye en esta motivación es la valoración del goce físico y la presión académica, que impulsa a los jóvenes de ambos sexos a buscar formas de distensión.

Esta motivación es cumplida por medio de determinado tipo de actividades. Entre ellas ocupan un lugar importante el «carrete» (fiesta, «party»), los deportes, la música, la danza y los paseos. 
[El tenis] Me pone eufórico [...] que tiene, que me gusta la combinación que tiene uno tiene que usar estrategia y al mismo tiempo tiene que combinarlo eso con fuerza [...] Con la agilidad y todo eso, me gusta eso (EII, 23, 29, 31).

En los diferentes medios, jugar a la pelota es un tema recurrente que genera fuertes emociones y sensaciones físicas. Las consecuencias de las actividades son el bienestar emocional y el sentimiento de ser competente. En este sentido, tienen un efecto positivo sobre el estado de ánimo, influyen en la conexión con sus sentimientos de alegría, la emoción intensa («adrenalina»), el «olvido» de las presiones y dificultades, y la relajación. Por otra parte, les ayudan a sentirse fuertes, capaces, ágiles, a movilizar sus energías y sentir gozo en general.

Hay algunos factores que mantienen y facilitan este tipo de experiencias. Entre ellos se cuentan especialmente los espacios poco estructurados, en los que los jóvenes sienten libertad de acción, oportunidad de moverse espontáneamente, ser activos, participativos y protagonistas en el desarrollo de la actividad. Estos espacios permiten el despliegue de la energía y creatividad. Un buen ejemplo lo constituyen los ambientes deportivos, artísticos y al aire libre en general.

Los elementos obstaculizadores son, por el contrario, espacios altamente estructurados y generalmente cerrados, que permiten poco movimiento, poca participación, y que generan pasividad. También se alude a espacios en los que los hombres y mujeres jóvenes se sienten descalificados y/o poco apoyados.

iv) Motivación de servir a otros a diferentes niveles

La pobreza, los problemas ecológicos y personas necesitadas de apoyo en general motivan a los jóvenes a brindar ayuda. Aunque estas acciones suelan implicar algún grado de sacrificio y se piense que su aporte es limitado, se le otorga sentido.

Es que yo creo en Dios, entonces igual yo, como se llama, yo voy a los desayunos de Jesús que son los días domingo a las cinco de la mañana [...] Entonces, si uno cree en Dios, en el pobre ve a Jesús vivo ahí, entonces por eso a mí me gusta ir, me gusta ayudar a la gente $(\mathrm{EI}, 8,10)$.

En esta línea, los hombres y mujeres jóvenes reportaron diversas acciones de ayuda. Entre ellas se cuenta construir mediaguas en poblaciones, dar desayunos de madrugada a personas pobres en la calle, 
misionar en el campo, reciclar desechos, participar en manifestaciones a favor de cambio en la sociedad, ser monitor de programas eclesiales para jóvenes, y finalmente ayudar a gente necesitada en forma puntual. Algunos fragmentos que ilustran este espíritu son:

Aportar algo, aportar algo a creo [...] de la vida [...] de la sociedad hay que cambiarla, entonces como cambiar algo, aportar tu granito de arena para que cambie por ejemplo, para que [¿En qué sentido cambie?] Socialmente, culturalmente (EII, 147, 149).

Las consecuencias experimentadas son el bienestar emocional, representado por el hecho de sentirse «lleno», calmar la conciencia, el sentimiento de alivio al contribuir, de autoeficacia y también el ser objeto de admiración por parte del grupo de pares.

Algunos factores facilitadores de esta actitud de preocupación por los demás son ciertos espacios eclesiales parroquiales y escolares con una orientación a la misión solidaria en la ciudad o el campo, en beneficio de personas material o espiritualmente necesitadas. También incide la creencia en Dios que impulsa a jóvenes a ayudar. A su vez, influyen los modelos paternos con actitudes de ayuda.

Entre los factores obstaculizadores se cuentan la falta de infraestructura para aportar a la ecología (tecnología apropiada), el cansancio posterior a la jornada de trabajo, el individualismo en Chile y la valoración negativa de la manifestación pública en pro de una causa.

\section{Discusión}

Tradicionalmente se ha considerado a la religión como el espacio catalizador de la experiencia, trascendencia y sentido de vida del individuo (Berger, 1969; Caillois, 2006). Si bien en la modernidad y, especialmente, en nuestros tiempos, la religión se ha visto desplazada por nuevas y complejas formas de entrega de sentido, hemos logrado constatar en el presente estudio que la experiencia religiosa sigue teniendo un espacio importante en las formas de estar, hacer y sentir de los jóvenes de ambos sexos del estudio. Aun cuando su rechazo hacia la institucionalidad religiosa — reflejada en la iglesia católica especialmente - es evidente, resulta significativo constatar que los jóvenes están desplegando, en sus estilos y formas de vida, otras formas de apropiación de la herencia católica tradicional. Es decir, prescinden de las orientaciones normativas tradicionales que 
la Iglesia católica ha desplegado en los últimos años, pero, al mismo tiempo, se apropian de elementos que le son constitutivas a ella y son capaces de revertir, transformar y/o redefinir los aspectos que para ellos les son significativos para la construcción de sus proyectos biográficos.

Desde una mirada teórica —y según los antecedentes empíricos aquí presentados-, se puede anotar que los procesos de individuación de los jóvenes de este estudio están experimentando un relativo aceleramiento. En las narraciones de los hombres y mujeres jóvenes se constata un evidente desfase entre sus procesos de individuación y los procesos de individualización de la institucionalidad, en este caso, religiosa. Esta última, especialmente, aumenta su brecha en la medida en que los jóvenes sienten que ella rechaza y juzga las áreas donde justamente han ganado los mayores márgenes de autonomía: la experimentación con el cuerpo, el goce, la sensación de libertad sexual, la ampliación de sus márgenes de sociabilidad, sus nuevas formas de comportamiento, nuevos usos de los espacios sociales y naturales, nuevas estéticas del cuerpo y de lugares físicos, la experiencia independiente de recogimiento e introspección, las acciones espontáneas, no planificadas y poco estructuradas, entre otras.

Si bien este desfase resulta evidente, hay antecedentes relevantes que señalan que la religión aún mantiene algún tipo de permanencia en los jóvenes. Destaca, por ejemplo, la creencia y relación con Dios, al que buscan sin fronteras espaciales, en la naturaleza y en la intimidad. También lo visualizan en personas solidarias, trascendiendo el espacio sagrado institucional. Lo evocan, además, en momentos emocionales más intensos, como un apoyo, una fuerza que ayuda a avanzar y una protección. Se relacionan con Él a través de la conversación, y de símbolos cargados de afecto y seguridad.

Esta permanencia también se manifiesta en las creencias y vivencias que los jóvenes dicen tener en sus ámbitos de sentidos de vida y espiritualidad. Junto con los soportes más centrales para ellos — su familia y sus amigos-, los ámbitos de espiritualidad son un aspecto central para su experimentación y construcción de sus intereses biográficos. Ellos ofrecen, en parte, los soportes que les permiten experimentar el mundo con sentimientos de entrega, cuidado, afecto, seguridad, pasión y amor por su prójimo (solidaridad) y su entorno (por ejemplo, la naturaleza). En ellos se logra el resguardo de lo íntimo, su bienestar emocional y el soporte para el logro de sus sueños. De esta forma, los jóvenes de ambos sexos logran desplegar sus normas, creencias, vivencias y expectativas de vida, configurando un joven 
dinámico, actualizado con las tendencias, tolerante con la diferencia y, por sobre todo, confiado en sí mismo y sus deseos de vida.

Desde un ángulo interpretativo del término espiritualidad, estos sentidos de vida y sus consecuencias —anidados en relaciones de afecto, espacios de recogimiento e interioridad, sensaciones de estar intensamente vivo-, remiten a atributos de amor, paz y vida que se están deseando, aun sin nombrar necesariamente la palabra Dios. Dichas motivaciones se intentan actualizar tanto en una relación explícita con Dios como mediante otro tipo de actividades ligadas al arte y cultura, naturaleza y sociabilidad, entre otras. Este tipo de búsquedas se experimenta en el contexto de una sociedad con complejas e intensas presiones y debilitadas ofertas de seguridad (PNUD, 2002).

Como anotáramos en la primera parte del texto, la necesaria dependencia mutua entre la subjetividad de las personas y la organización institucional de la sociedad se ve tensionada por aquella doble llamada a la autonomía (Beck y Beck-Gernsheim, 2003). De esta forma, y a partir de los resultados aquí presentados, resulta central debatir sobre las dependencias que, en el espacio de la cultura, acontecen entre los individuos y las instituciones (Güell, 2008). De ahí que, finalmente, los actuales cambios y/o la radicalización de los cambios aquí evidenciados signifiquen un gran desafío social y cultural para las sociedades actuales. Si bien las respuestas institucionales eclesiales hacia la juventud han logrado responder parcialmente a las motivaciones y búsquedas de los jóvenes, se constata que aún es evidente que falta un reconocimiento y legitimidad de los cambios juveniles en las esferas institucionales como opciones válidas de sentido.

En conclusión, la individuación de los jóvenes de ambos sexos y los procesos de individualización de las instituciones en la modernidad tardía, líquida o incompleta, está, en el caso de Chile, en una tensión permanente y difusa. El descalce aparente exhibido en esta investigación por parte de los jóvenes y la institucionalidad religiosa católica deja en evidencia la necesidad de ampliar los debates en torno a cómo construimos las lógicas de autonomía moderna entre ambas dimensiones y, sobre todo, cómo se convive en una sociedad que experimenta esas tendencias en un contexto global.

SANTIAGO (Chile), AGOSTO 2010

RECIBIDO: SEPTIEMBRE 2010

ACEPTADO: OCTUBRE 2010 


\section{REFERENCIAS BIBLIOGRÁFICAS}

ARCHER, MARgARET (1997): El lugar de la cultura en la teoría social. Buenos Aires: Ediciones Nueva Visión.

BAuman, Zygmunt (2003): Modernidad líquida. México: FCE.

— (2001): La posmodernidad y sus desencantos. Madrid: Akal.

BECK, UlRICH (2001): El normal caos del amor: las nuevas formas de la relación amorosa. Barcelona: Paidós.

— y BeCK-GERNSHEIM, ELISABETH (2003): La individualización: el individualismo institucionalizado y sus consecuencias sociales y políticas. Barcelona: Paidós.

Berger, Peter (1969): El dosel sagrado: elementos para una sociología de la religión. Buenos Aires: Amorrortu.

BILBAO, ANDRÉs (2007): Individuo y orden social. La emergencia del individuo y la transición a la sociología. Madrid: Ediciones Sequitur.

CAILlois, Roger (2006): El hombre y lo sagrado. México: FCE.

CISOC (2005): Jóvenes: orientaciones valóricas, religión e iglesia católica. Estudio realizado en base a jóvenes de cuarto medio de colegios de Santiago. Santiago: Ediciones Cisoc-Bellarmino.

(2003): «¿Dónde han ido los pecadores?» Boletín Pastoral CISOCBellarmino $\mathrm{N}^{\circ} 90$. Santiago: Ediciones Cisoc-Bellarmino.

EMBLEN, J. D. (1992): «Religion and spirituality defined according to current use in nursing literature». Journal of Professional Nursing No8. California: University of California.

GIDDENS, ANTHONY (1997): Modernidad e identidad del yo: el yo y la sociedad en la época contemporánea. Barcelona: Ediciones Península.

- (1992): La transformación de la intimidad. Sexualidad, amor y erotismo en las sociedades modernas. Madrid: Cátedra.

— (1984): La constitución de la sociedad: bases para la teoría de la estructuración. Buenos Aires: Amorrortu.

GidDENS, ANTHONY y JosetXo BERIAIN (1996) (compiladores): Las consecuencias perversas de la modernidad: modernidad, contingencia y riesgo. Barcelona: Ediciones Anthropos.

GÜELL, PEDRO (2008): «¿Qué se dice cuando se dice cultura? Notas sobre el nombre de un problema». Revista de Sociología N²2. Santiago: Ediciones Facultad de Ciencias Sociales, Universidad de Chile.

HABERMAS, JÜRGEN (1998): «Modernidad: un proyecto incompleto» Revista Punto de Vista $\mathrm{N}^{\circ} 21$. Buenos Aires: Ediciones Punto de Vista.

HARRIET, I. y G. VALDIVIESO (1990): «Actitudes, valores y opiniones de alumnos de cuarto medio de colegios católicos». Revista Estudios Sociales $\mathrm{N}^{\circ} 64$. Santiago: Ediciones CPU.

InJUV (2007): V Encuesta nacional de juventud. Santiago: INJUV. 
MARdones MARTínez, José MARÍA (1980): Para comprender las nuevas formas de la religión: la reconfiguración postcristiana de la religión. Madrid: Editorial Verbo Divino.

MARTUCCELli, DANILO y KATHIA ARAUJO (2010): «La individuación y el trabajo de los individuos». Educação e Pesquisa Vol. 36. São Paulo: Ediciones Universidade de São Paulo.

MidePlan (2000): Los jóvenes chilenos: cambios culturales; perspectivas para el siglo XXI. Santiago: MIDEPLAN.

PETEET, J. R., (1994): «Approaching spiritual problems in psychotherapy: a conceptual framework». Journal of Psychotherapy Practice and Research No3. Arlington: American Psychiatric Publishing.

PNUD (2010): Género: los desafíos de la igualdad. Santiago: PNUD. (2002): Nosotros los chilenos. Un desafío cultural. Santiago: PNUD.

— e INJUV (2004): Transformaciones culturales e identidad juvenil en Chile. Santiago: PNUD e INJUV.

STRAUSS, A. L. y J. CORBIN (1990): Basics of qualitative research. Newbury Park/London/New Delhi: Ediciones Sage.

TINOCO-AMADOR, JosuÉ (2009): «Identificando los constructos de la religiosidad para jóvenes universitarios en México». Universitas Psychologica Vol. 8. México: Ediciones Universidad Autónoma Metropolitana.

WAGNER, PETER (1997): Sociología de la modernidad. Libertad y disciplina. Barcelona: Editorial Herder. 